\title{
Genotoxic effects of anoxia on Mytilus galloprovincialis
}

\author{
R. Brunetti, O. Fumagalli, P. Valerio, M. Gabriele \\ Department of Biology, University of Padova, Via Trieste 75, I-35121 Padova, Italy
}

\begin{abstract}
In mussels Mytilus galloprovincialis Lmk exposed to the air or kept in oxygen-free seawater, the frequency of micronuclei detected in gill tissues significantly rises as a function of time. It is suggested that the genotoxic agent may be a product of anaerobic metabolism, and the genotoxicity of propionic and acetic acid are shown, although the possibility that other substances may be involved in the phenomenon is not excluded.
\end{abstract}

\section{INTRODUCTION}

In the marine environment anoxia is a phenomenon generally localized though not rare. Bottom-living marine animals are subjected to hypoxic or anoxic conditions as a consequence of particular hydrodynamic conditions or eutrophication of waters. Anoxia is of course recurrent in animals living in the intertidal zone. Mussels react to exposure to air or to reduced oxygen contents of waters by closing their valves and changing to anaerobic metabolism (De Zwaan \& Wijsman 1976, Gäde 1983).

In a previous study on the micronucleus test in Mytilus galloprovincialis Lmk. we observed an unexpectedly high frequency of micronuclei in gill tissues of mussels kept in air either at room temperature or in the cold, suggesting that this effect may be due to the genotoxic activity of some catabolic product of their anaerobic metabolism (Brunetti et al. 1988). In fact micronuclei, which are small chromatid bodies formed during telophase near the principal nucleus as a consequence of chromosome breakage or loss of an entire chromosome during anaphase, may be used as an index of chromosome damage (= genotoxicity) (Heddle et al. 1983, Keith \& Balder 1989).

In the present study we confirm our previous observations showing that in anoxic mussels the micronucleus frequency rises. Moreover, since the most important end-products of the anaerobic metabolism of Mytilus spp. are propionic and acetic acid (De Zwaan 1977, Van Den Thillart \& De Vries 1985), we tested the micronucleus-inducing ability of these 2 carboxylic acids.

\section{MATERIALS AND METHODS}

Mussels for experiments were collected in different seasons from cultures in the Venetian Lagoon, Italy, cleared of epibionts, and transferred within $1 \mathrm{~h}$ to laboratory aquaria at the same temperature as the natural waters. In each set of experiments mussels of the same age and approximately the same size were used.

Exposure to air at different temperatures. In these experiments the effects of air exposure at 2 temperatures $\left(5\right.$ and $25^{\circ} \mathrm{C}$ ) on micronucleus frequencies were tested on sexually ripe (October 1988 \& February 1989) and unripe (June 1989) mussels.

Exposure to air at different temperatures and anoxic water. To study the effects on micronucleus frequencies of air exposure and anoxic water at the same temperature at which the mussels were collected, 2 experiments were performed at 10 and $25^{\circ} \mathrm{C}$ with ripe (March 1990) and unripe (June 1990) mussels. Effects of air exposure were also tested on mussels whose valves were tied to avoid any exchange with the atmosphere, since it has been reported that some mussel species open their valves during exposure to air, suggesting some use of atmospheric oxygen (Bayne et al. 1976b, Ahmad \& Chaplin 1977). A slight degree of shell gape was reported in Mytilus edulis (Coleman 1973) and $M$. californianus (Bayne et al. 1976a), and was also observed by us in $M$. galloprovincialis.

Experiments in anoxic water were performed in sealed $500 \mathrm{ml}$ vials filled with filtered water, with only 1 mussel per vial. The oxygen content of the water was reduced by flushing with nitrogen and was checked at 
the beginning and end of experiments with an oximeter. Dissolved oxygen ranged from 0.5 to $0.8 \mathrm{ppm}$. Lower values were discarded to avoid the formation of hydrogen sulphide.

Exposure to propionic and acetic acids. Treatments with propionic and/or acetic acid were performed in glass aquaria, and the conditioned water was renewed every $6 \mathrm{~h}$. Concentrations of propionic acid used were 4 and $0.3 \mathrm{mM} \mathrm{l}^{-1}$ and for acetic acid 2 and $0.1 \mathrm{mM} \mathrm{l}^{-1}$. Length of treatment was either 6,48 or $72 \mathrm{~h}$. Genotoxic effects were detected by means of the micronucleus test (Heddle et al. 1983). According to the technique, more extensively described in Brunetti et al. (1992) (this issue), the gills were removed from mussels 0 or 2 and $10 \mathrm{~d}$ after the end of treatment, enzymatically digested and the obtained cell-suspension fixed with methanol:acetic acid $(3: 1)$ and centrifuged. The resulting pellets were spread on slides, air-dried and stained with $5 \%$ Giemsa. Two thousand cells per mussel were scored.

\section{RESULTS AND DISCUSSION}

\section{Effects of air exposure}

Effects of air exposure at 2 temperatures on micronucleus frequencies are shown in Fig. 1. In all cases a linear increase as a function of time was observed, although in the June 1989 mussels exposed to air at low temperature this increase occurred after only $3 \mathrm{~d}$ of treatment (Fig. 1C). This may be due to a temporary metabolic pause as a consequence of the sudden passage from the high summer environmental temperature (about $25^{\circ} \mathrm{C}$ ) to the cold experimental one $\left(5^{\circ} \mathrm{C}\right.$ )

Fig. 1 also indicates that induced micronucleus frequencies rapidly fell to control values when mussels were immersed in water at $15^{\circ} \mathrm{C}$.

\section{Effects of air exposure and anoxic water}

Results of changes in air temperature and of anoxic water experiments are shown in Fig. 2. Responses of ripe and unripe mussels at the 3 experimental conditions did not differ, although the increase in micronucleus frequencies was more rapid at $25^{\circ} \mathrm{C}$. A statistically significant difference from controls was noted on Days $3 \& 4$ of treatment at 25 and $10^{\circ} \mathrm{C}$ respectively.

These results are not in agreement with the concept that in periods of oxygen-deficiency mussel metabolism falls at a 'standard' temperature-independent rate (Newell \& Northcroft 1967, Coleman 1973). In fact, in anoxic individuals anaerobic metabolism may be briefly involved, nullifying the meaning of oxygen uptake in evaluating energy demands (De Zwaan \& Wijsman 1976).

A trend towards diversification among the 3 experimental conditions as a function of time was also noted. This may indicate easier removal of the genotoxic agent in air-exposed mussels with free valves or a lower accumulation of toxic agents as a consequence of the aerial rate of oxygen uptake (Widdows et al. 1979).

\section{Effects of propionic and acetic acids}

This set of experiments was performed to test the hypothesis that the genotoxic agent(s) acting during anoxia may be propionic and/or acetic acid, which are the most important end-products of anaerobic metabolism in these mussels (De Zwaan 1977).

Table 1 shows the results of the 3 preliminary experiments. The concentrations tested in Expts 2 \& 3 were chosen on the basis of the study of Van Den Thillart \& De Vries (1985), who found 0.3 and $0.1 \mathrm{mmol}$ of propionic and acetic acids respectively in the water sur-
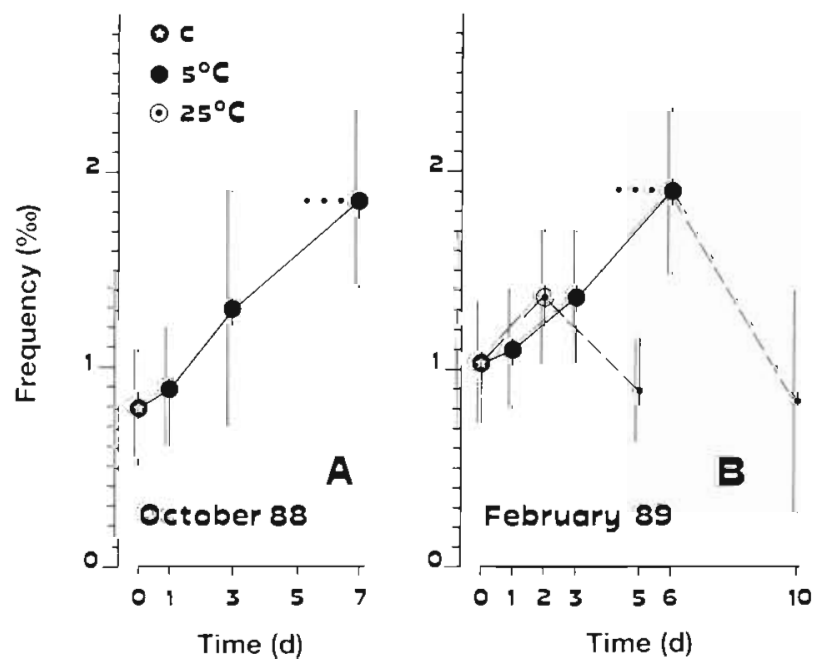

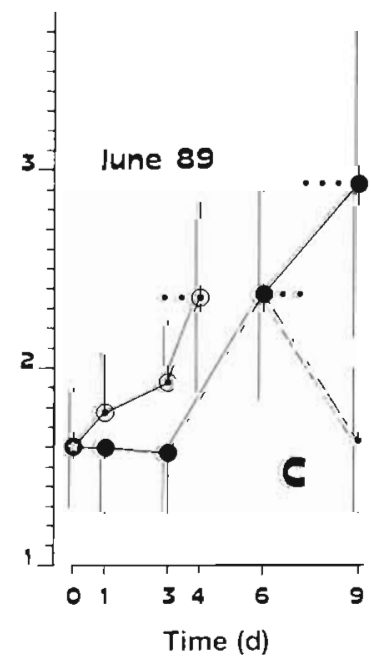

Fig. 1. Mytilus galloprovincialis Ordinate: mean micronuclei frequency $(\%)$ induced by air exposure at 5 and $25^{\circ} \mathrm{C}$ in ripe (A October 1988; B: February 1989) and unripe (C: June 1989) mussels; abscissa: time in days. Vertical bars: $95 \%$ confidence limit of mean (10 mussels per experimental point, 2000 cells ind. ${ }^{-1}$ y. Dashed lines: pattern of frequencies after reimmersion. Statistically significant differences from controls $(c)$ : $\cdots=p<0.01 ; \cdots=$ $\mathrm{p}<0.001)$ 
Fig. 2. Mytilus galloprovincialis. Ordinate: mean micronuclei frequency $(\%)$ induced in air-exposed mussels with free ( $\mathrm{fv}$ ) and tied (tv) valves and in individuals kept in anoxic water (aw). A: Ripe mussels (March 1990); B: unripe mussels (June 1990); abscissa: time in days. Vertical bars: $95 \%$ confidence limit of mean (10 mussels per experimental point, 2000 cells ind.$^{-1}$ ). Statistically significant differences from controls (c): ${ }^{\cdots}=$ $\mathrm{p}<0.01 ; \cdots=p<0.001)$
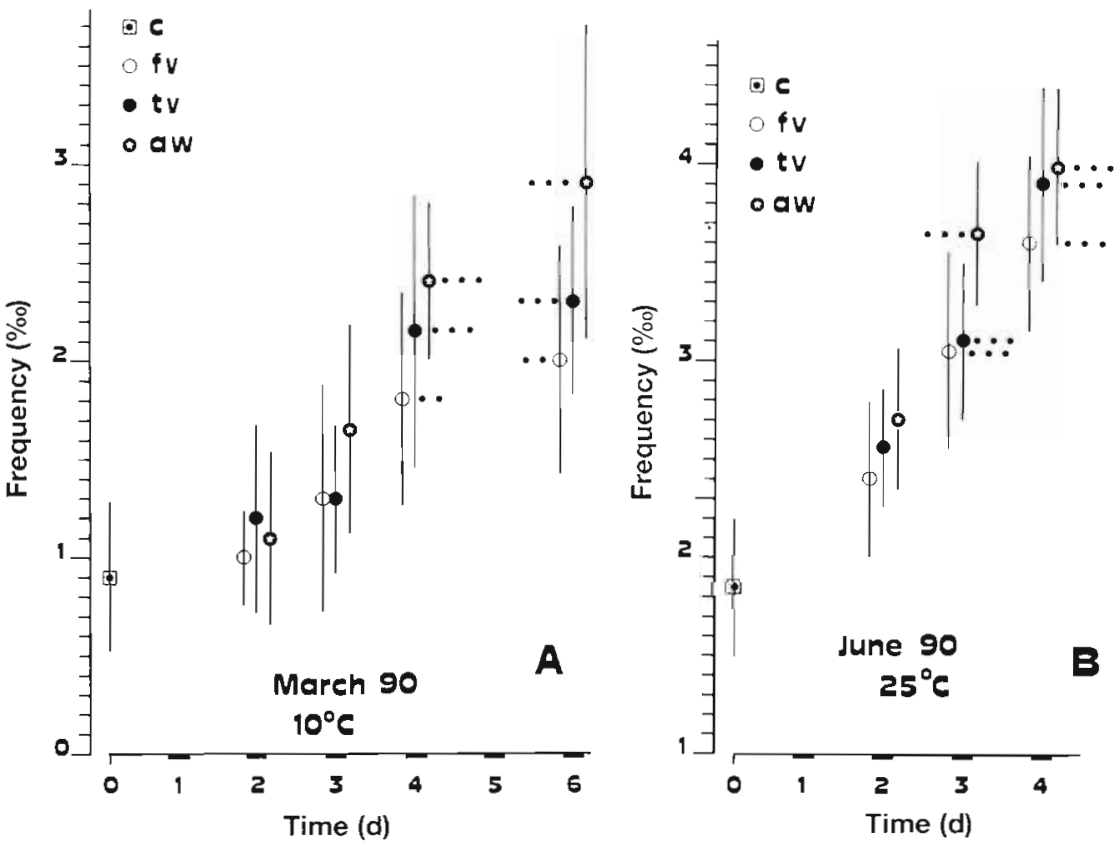

rounding Mytilus edulis after $3 \mathrm{~d}$ of anoxia at $10^{\circ} \mathrm{C}$. These data indicate that both substances are genotoxic. Moreover, because the ratio of the increase of mean micronucleus frequencies induced by propionic and acetic acids compared to that of controls is about 1.4, and the ratio of the contration of propionic acid and acetic acid used was about 3 , it is inferred that acetic acid is more toxic.

During treatments specimens maintained apparently normal rates of filtration and defecation. However, after $6 \mathrm{~h}$ of treatment at the high acid concentrations of Expt 1 the mussels showed an excessive degree of shell gape and no reaction to tactile stimuli. When transferred to unconditioned seawater, mussels returned to normality in a few hours. Ten days after the end of
Expt 1, only mussels previously treated with propionic acid had micronucleus frequencies significantly higher than those of controls.

Fig. 3A, B shows the results of 2 other experiments performed on (A) unripe and (B) ripe mussels at the same environmental temperature at which the animals had been collected. These data indicate the probable additive effect of the 2 acids when used together.

A substantial difference was also observed between the 2 experiments. In (A), micronucleus frequencies mainly rose after the end of treatment, while in (B) the highest increase took place in the presence of the acids and, at least for micronuclei induced by propionic acid, decay immediately occurred after the end of treatment. At present, no elements allow us to infer whether this

Table 1. Mytilus galloprovincialis. Micronuclei frequency $\left(\times 10^{3}\right)$ induced by acetic and propionic acids. $T$ : time (d) from end of treatment; $\bar{x}$ : mean; $\mathrm{SD}$ : standard deviation; $\mathrm{p}$ : statistical comparison with controls; $\mathrm{p}<0.5, \cdots p<0.001$, ns: not significant. Sample size $=10 ; 2000$ cells ind. ${ }^{-1}$

\begin{tabular}{|c|c|c|c|c|c|c|c|c|c|c|c|c|}
\hline & \multicolumn{4}{|c|}{$\begin{array}{c}\text { Expt } 1 \\
6 \mathrm{~h} \text { treatment }\end{array}$} & \multicolumn{4}{|c|}{$\begin{array}{c}\text { Expt } 2 \\
48 \mathrm{~h} \text { treatment }\end{array}$} & \multicolumn{4}{|c|}{$\begin{array}{c}\text { Expt } 3 \\
72 \mathrm{~h} \text { treatment }\end{array}$} \\
\hline & $T$ & $\bar{X}$ & $\mathrm{SD}$ & $\mathrm{p}$ & $T$ & $\bar{x}$ & $\mathrm{SD}$ & $\mathrm{p}$ & $T$ & $\bar{X}$ & $\mathrm{SD}$ & $p$ \\
\hline \multirow[t]{3}{*}{ Propionic acid conc. } & \multicolumn{4}{|c|}{$4 \mathrm{mM} \mathrm{l}^{-1}$} & \multicolumn{4}{|c|}{$0.3 \mathrm{mM} \mathrm{l}^{-1}$} & \multicolumn{4}{|c|}{$0.3 \mathrm{mM} \mathrm{l}^{-1}$} \\
\hline & 2 & 6.14 & 2.09 & $\cdots$ & 0 & 4.25 & 1.63 & $\cdots$ & 0 & 4.66 & 1.68 & $\cdots$ \\
\hline & 10 & 1.96 & 0.96 & $\cdot$ & & & & & & & & \\
\hline \multirow[t]{3}{*}{ Acetic acid conc. } & \multicolumn{4}{|c|}{$2 \mathrm{mMl}^{-1}$} & \multicolumn{4}{|c|}{$0.1 \mathrm{mM} \mathrm{l}^{-1}$} & \multicolumn{4}{|c|}{$0.1 \mathrm{mM} \mathrm{l}^{-1}$} \\
\hline & 2 & 4.50 & 1.35 & $\cdots$ & 0 & 3.35 & 1.75 & $\cdots$ & 0 & 3.52 & 0.87 & $\cdots$ \\
\hline & 10 & 1.47 & 0.75 & ns & & & & & & & & \\
\hline Controls & 0 & 0.90 & 0.81 & 0 & & & & & & & & \\
\hline
\end{tabular}




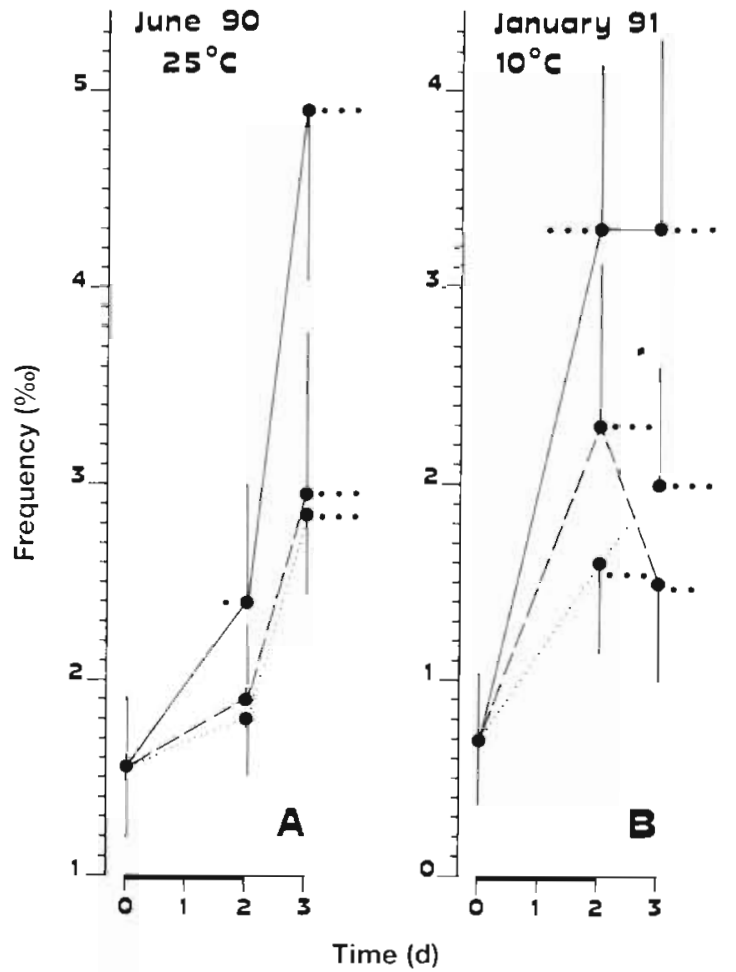

Fig. 3. Mytilus galloprovincialis. Ordinate: mean micronuclei frequency $(\%)$ induced by propionic acid $(0.3 \mathrm{mmol}$ ) (dashed line), acetic acid $(0.1 \mathrm{mmol})$ (dotted line) and by the 2 acids together (solid line); abscissa: time in days; black bar: length of the treatment. Vertical bars: $95 \%$ confidence limit of mean (only half interval is drawn) (10 mussels per experimental point, 2000 cells ind. ${ }^{-1}$ ). Statistically significant differences from controls: $(\cdots=p<0.01 ; \cdots=p<0.001)$

different trend is due to the direct effect of experimental temperature or to the different physiological state of the mussels.

In conclusion, the present data clearly show that anoxia, due both to a lack of oxygen in water and to exposure to air, can induce genotoxic damage in mussel gill tissue and that propionic and acetic acid have genotoxic activity. Thus we can plausibly suppose that these acids could be the cause of the increase in micronucleus frequency detected in anoxic mussels. Kluytmans et al. $(1978,1980)$ showed that in $2 \mathrm{~d}$ airexposed mussels, the acetate production is not influenced by the thermal trend while the lag period between the onset of anoxia and the beginning of propionate synthesis as well as the rate of its synthesis are strongly temperature dependent. Consequently the slower increment in micronucleus frequency observed in anoxic animals at $10^{\circ} \mathrm{C}$ as compared with those at $25^{\circ} \mathrm{C}$ (Fig. 2) might be due to a minor concentration of

This article was submitted to the editor the genotoxic agent rather than a slower mitotic rate occurring in the former.

Acknowledgements. This study was supported by grants from Italian Ministry of Scientific Research (MURST).

\section{LITERATURE CITED}

Ahamad, T. A., Chaplin, A. E. (1977). The intermediary metabolism of Mytilus edulis (L.) and Cerastoderma edule (L.) during exposure to the atmosphere. Biochem. Soc. Trans. 5: 1320-1323

Bayne, B. L., Bayne, C. J., Carefoot, T. C., Thompson, R. J (1976a). The physiological ecology of Mytilus californianus Conrad. 1. Metabolism and energy balance. Oecologia 22: 211-228

Bayne, B. L., Thompson, R. J., Widdows, J. (1976b). Physiology: I. In: Bayne, B. L. (ed.) Marine mussels: their ecology and physiology. Cambridge University Press, London, $\mathrm{p}$. 121-206

Brunetti, R., Majone, F., Gola, I., Beltrame, C. (1988). The micronucleus test: examples of application to marine ecology. Mar. Ecol. Prog. Ser. 44: 65-68

Brunetti, R., Gabriele, M., Valerio, P., Fumagalli, O. (1992). The micronucleus test: temporal pattern of the base-line frequency in Mytilus galloprovincialis Lmk. Mar. Ecol. Prog. Ser. 83: 75-78

Coleman, N. (1973). The oxygen consumption of Mytilus edulis in air. Comp. Biochem. Physiol. 45A. 393-402

De Zwaan, A. (1977). Anaerobic energy metabolism in bivalve molluscs. Oceanogr mar biol. A. Rev. 15: 103-187

De Zwaan, A., Wijsman, T. C. M. (1976). Anaerobic metabolism in bivalvia (Mollusca). Characteristics of anaerobic metabolism. Comp. Biochem. Physiol. 54B: 313-324

Gäde, G. (1983). Energy metabolism of Arthropods and Mollusks during environmental and functional anaerobiosis. J. exp. Zool. 228: 415-429

Heddle, J. A., Hite, M., Kirkhart, B., Mavournin, K., McGregor, J. T., Newell, G. W., Salamone, M. F. (1983). The induction of micronuclei as a measure of genotoxicity. A report of the U.S. Environmental Protection Agency Gene-Tox Program. Mutation Res. 123: 61-118

Keith, L. S., Baldev, K. V (1989). Micronuclei, kinetochores and hypoploidy: tests with some agents. Mutagenesis 4: 425-431

Kluytmans, J. H., Graft, M., van Janus, J., Pieters, H. (1978). Production and excretion of volatile fatty acids in the sea mussel Mytilus edulis L. J. comp. Physiol. 123: 163-167

Kluytmans, J. H., Zandee, D. I., Zurburg, W., Pieters, H. (1980). The influence of seasonal changes on energy metabolism in Mytilus edulis (L.). III Anaerobic energy metabolism. Comp. Biochem. Physiol. 67B: 307-315

Newell, R. C., Northcroft, H. R. (1967). A re-interpretation of the effect of temperature on the metabolism of certain marine invertebrates. J. Zool., Lond. 151: 277-298

Van Den Thillart, G., De Vries, I. (1985). Excretion of volatile fatty acids by anoxic Mytilus edulis and Anodonta cygnea. Comp. Brochem. Physiol. 80B: 299-301

Widdows, J., Bayne, B. L., Livingstone, D. R, Newell, R. I. E. Donkin, P. (1979). Physiological and biochemical responses of bivalve molluscs to exposure to air. Comp. Biochem. Physiol. 62A: 301-308

Manuscript first recelved: September 11, 1991

Revised version accepted: April 21, 1992 